\title{
Comparison between supraclavicular and infraclavicular approaches for subclavian venous catheterization in adults
}

\author{
S Govindswamy ${ }^{1}$, AM Shamanna ${ }^{1 *}, P$ Gowda ${ }^{2}$ \\ Assistant Professor ${ }^{l}$, Resident ${ }^{2}$, MS Ramaiah medical College, Bangalore, India.
}

\begin{abstract}
Introduction: The subclavian vein access has been the standard recommended approach for central venous catheterization both for short and long-term use. Aim is to compare the supraclavicular and infraclavicular approaches for subclavian venous cannulation in regard to success, attempts required, time taken and complications.

Material and Methods: All patients satisfying the inclusion criteria were placed either in group supraclavicular (S) or group infraclavicular (I) approach for right subclavian vein and 7FrG cannula was cannulated using modified Seldinger technique under general anaesthesia.

Results: Time taken for successful cannulation in Group (S) were $188.96 \pm 37.19$ seconds and in Group (I) were $299.76 \pm 69.712$ seconds which was statistically significant with $\mathrm{p}$ value of $<0.001$. Success of cannulation in Group (S) was $95 \%$, where as in Group (I) was $92.5 \%$. In Group (S) $85 \%$ cannulas were secured in $1^{\text {st }}$ attempt, $10 \%$ in $2^{\text {nd }}$ attempt and 5\% had failed cannulation. In Group (I) $67.5 \%$ were secured in $1^{\text {st }}$ attempt, $25 \%$ in $2^{\text {nd }}$ attempt and $7.5 \%$ had failed cannulation. Complications in terms of arterial puncture, malposition and pneumothorax were comparable. All these parameters were not statistically significant between the groups with $\mathrm{p}$ value $>0.05$.

Supraclavicular approach is better than infraclavicular approach in terms of less mean time required for successful cannulation.

Conclusion: Subclavian venous catheterization via the supraclavicular approach is aquicker method of central venous access in anesthesia.
\end{abstract}

Keywords: Supraclavicular; infraclavicular; subclavian vein

\section{Introduction}

Central venous catheter (CVC) insertion is commonly used in critically ill patients and those undergoing major surgery for invasive monitoring technologies and aggressive haemodynamic resuscitation. The subclavian vein (SCV) is the preferred site for CVC insertion because of its large size, lower risk for infection and its ability to provide patient comfort in longterm use. ${ }^{1,2}$

Since Aubaniac's original description in 1952, subclavian vein catheterization via the infraclavicular approach has become a wellestablished technique. In 1965 an alternate supraclavicular approach was described by Yoffa

\footnotetext{
*Correspondence: AM Shamanna

Email: : ashok_m_s@hotmail.com

iD https://orcid.org/0000-0002-7983-0765
}

Received: $17 / 08 / 2017$

Accepted: 20/10/2017

DOI: http://doi.org/10.4038/slja.v26i1.8269

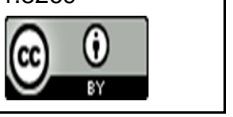

having some distinct advantages over the infraclavicular approach like a well-defined insertion landmark (the clavisternomastoid angle); a shorter distance from skin to vein; a larger target area; a straighter path to the superior vena cava; less proximity to the lung and fewer complications of pleural or arterial puncture. However, it is less often taught and utilized for reasons that are not clear. ${ }^{3,4}$

Hence this study was to compare supraclavicular and infraclavicular approaches for subclavian venous catheterization

Aim: To compare the supraclavicular and infraclavicular approaches for subclavian venous cannulation.

\section{Objectives:}

The purpose of this study was to compare the two techniques regarding:

1. Number of attempts

2. Time required for cannulation

3. Success rate of catheterization

4. Complications associated with the procedure (arterial puncture, malposition, pneumothorax/haemothorax) 


\section{Materials and Methods}

Patients who needed central venous catheterizations for purposes like fluid management and central venous pressure (CVP) monitoring were given importance. Randomization was done by computer-generated random number tables and divided into two groups Group S and Group I. Written informed consent was taken from all the patients after explaining to them and their attendants about the merits and demerits of the procedure. Patients satisfying the inclusion criteria were enrolled in the study. Study was conducted in M.S. Ramaiah Hospital, MSR Nagar, Bangalore following ethics committee approval from the hospital.Cannulation was performed by two trained anaesthetist with more than 3 years of experience.

Study period: July 2016 to April 2017

\section{Inclusion Criteria}

1. ASA Grading I, II, III

2. Medical, surgical and neurosurgical patients

3. Patients requiring CVP monitoring and infusion of vasopressors

4. Patients requiring long-term fluid management in the ICU.

\section{Exclusion Criteria}

1. Morbidly obese patients in whom landmarks were difficult to identify

2. Infection at the site of insertion

3. Trauma to ipsilateral neck/clavicle/first rib or deformities

4. Coagulopathy

5. Age $<18$ years

Routine investigations such as complete haemogram, bleeding time, clotting time, urine examination, coagulation profile, electrocardiogram and chest X-ray (PA view) were carried out in all patients.

Patients were given general anaesthesia with fentanyl $2 \mathrm{mcg} / \mathrm{kg}$, propofol $2 \mathrm{mg} / \mathrm{kg}$ and atracurium $0.5 \mathrm{mg} / \mathrm{kg}$ and male patients were intubated with $8-8.5 \mathrm{~mm}$ endotracheal tubes while female patients were intubated with $7-7.5 \mathrm{~mm}$ endotracheal tubes.

All patients were placed in a $10^{\circ}$ head-down position with a rolled towel placed under their shoulders. The head was turned $30^{\circ}$ away from the side of the venepuncture, and the ipsilateral arm was gently pulled towards the knee. Right subclavian vein was selected for cannulation. Subclavian vein was cannulated using $7 \mathrm{Fr} G$ cannula using modified Seldinger technique.

\section{Supraclavicular approach $(\text { Group } \mathbf{S})^{5}$}

The claviculosternomastoid angle was identified either by asking the patient to raise his/her head or by palpation. Correct identification of this angle is critical to the success of supraclavicular approach. The needle with attached syringe was inserted at the claviculosternomastoid angle, bisecting it in a direction at an angle of $45^{\circ}$. Needle was advanced behind the clavicle and directed towards the contralateral nipple. (Figure 1)

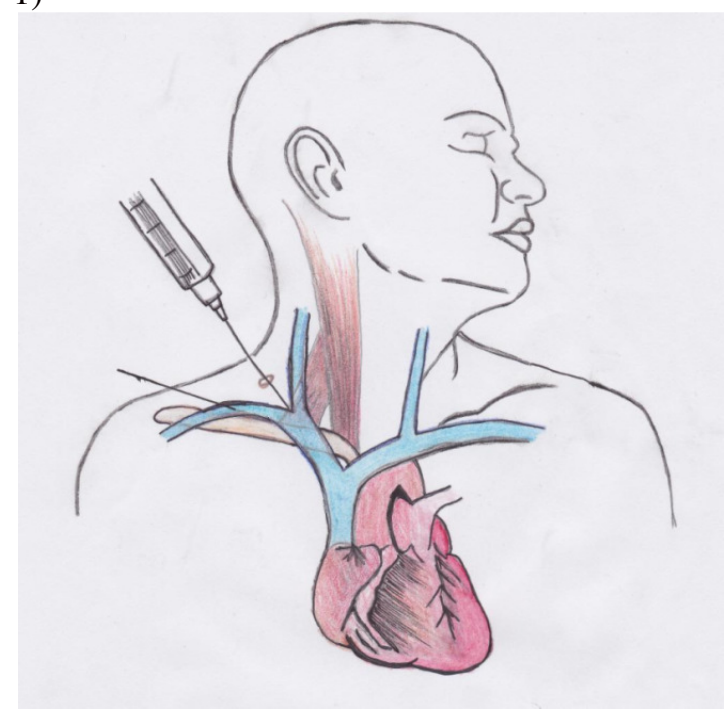

Figure 1: Supraclavicular approach

\section{Infraclavicular approach (Group I) ${ }^{6}$}

After identification of the anatomical landmarks, wide preparation of the surgical field, including infraclavicular and jugular area sterilization, was performed. Point of needle entry $1 \mathrm{~cm}$ below the clavicle at the junction of middle and medial third of the clavicle and directing the needle towards the suprasternal notch. (Figure 2) 


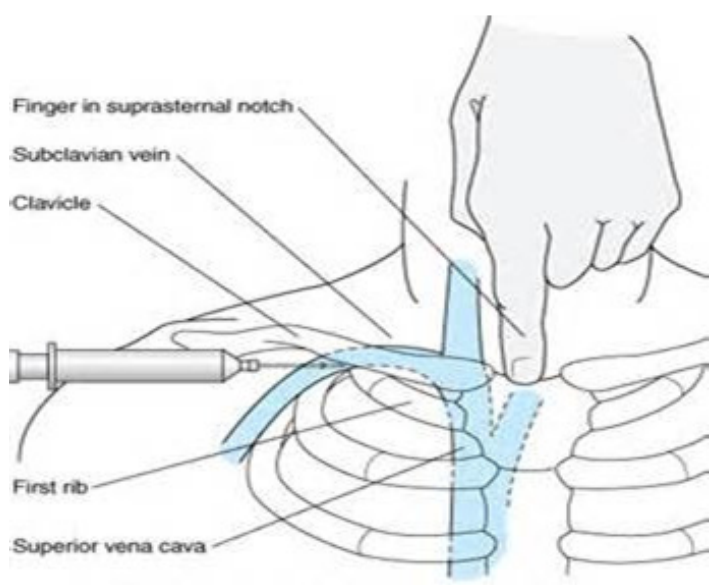

Figure 2: Infraclavicular approach

Parameters which were looked upon are number of attempts required for successful cannulation, time taken for the procedure, correct placement and complications.

Each skin puncture was defined as an attempt and maximum 3 attempts were allowed in either approach and in case of failure, alternate approach (internal jugular) was used for catheterization. Once the needle is taken off the skin it's counted as an attempt. Any further skin puncture is counted as new attempt.

Time taken is calculated in seconds (sec) from the skin puncture to successful placement of cannula.

All successful cannulations were confirmed by post-procedure chest radiography for correct placement and to check for any complications. Any mal positions like cannula tip being in ispsilateral or contralateral internal jugular vein (IJV) or contralateral subclavian were noted. Complications like arterial puncture was noted by bright red color of the blood and pulsatile flow, pneumothorax and haemothorax were visualised by chest $\mathrm{x}$-ray.

\section{Statistical methods}

Descriptive statistics of access time of catheterisation was analysed and presented in terms of mean with standard deviation. The success rate, number of attempts and complications were summarised in terms of percentage.

Independent $\mathrm{T}$ test was used to compare the access time of catheterisation between two groups. Chi square test was used to compare success rate, number of attempts and complications between two groups.
Thakur et $\mathrm{al}^{1}$, has observed that the mean access time in supraclavicular approach was $4.30 \pm$ $1.02 \mathrm{mins}$, where as in infraclavicular approach it was $6.07+2.14 \mathrm{mins}$. In the present study expecting similar results and to get $80 \%$ power, 95\% confidence level and minimum detectable difference in group as $1.1 \mathrm{~min}$, the study required a minimum of 36 subjects in each group. We considered 40 subjects to avoid drop rates during study.

\section{Results}

The mean age in group $S$ was $35.93 \pm 9.5$ years and group I was $39.53 \pm 8.4$ years. The mean weight was $65.1 \pm 6.9 \mathrm{kgs}$ and $58 \pm 6.9 \mathrm{kgs}$ in group $\mathrm{S}$ and I respectively. The mean height was $165.1 \pm 8.23 \mathrm{cms}$ and $156 \pm 10.1 \mathrm{cms}$ in group $\mathrm{S}$ and I respectively. Out of 80 patients, 38 were males and 42 were females. In group S, 16 were males and 24 were females. In group I, 22 were males and 18 were females.

The demographic parameters of the patients like age, weight, height and gender in the study were comparable with a $p$ value of $>0.05$. All these were statistically not significant.

In Group S out of 40 patients, in 34patients (85\%) cannulas were secured in $1^{\text {st }}$ attempt, 4 patients $(10 \%)$ in $2^{\text {nd }}$ attempt and 2 patients $(5 \%)$ had failed cannulation.

In Group I out of 40 patients, in 27 patients $(67.5 \%)$ cannula was secured in $1^{\text {st }}$ attempt, 10 patients $(25 \%)$ in $2^{\text {nd }}$ attempt and 3 patients (7.5\%) had failed cannulation. These were not statistically significant with $\mathrm{p}$ value of $>0.05$. (Figure 3)

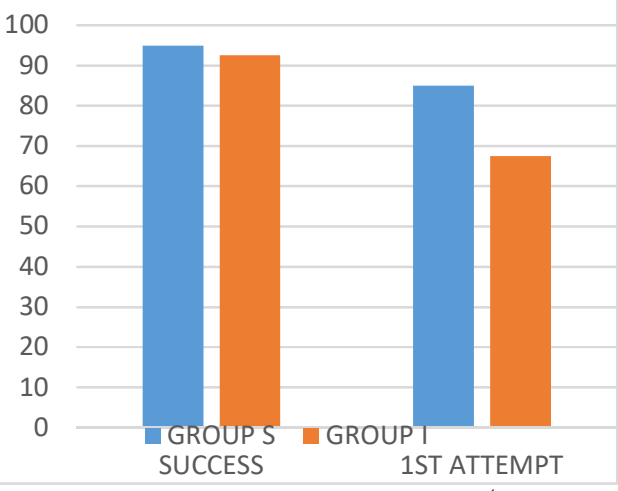

Figure 3: Comparison of success and $1^{\text {st }}$ attempt between two groups $\mathrm{S}$ and $\mathrm{I}$ in terms of percentage 
Time taken for successful cannulation in Group $\mathrm{S}$ were $188.96 \pm 37.19$ seconds and in Group I were $299.76 \pm 69.712$ seconds which was statistically significant with $p$ value of $<0.001$. (Figure 4 )

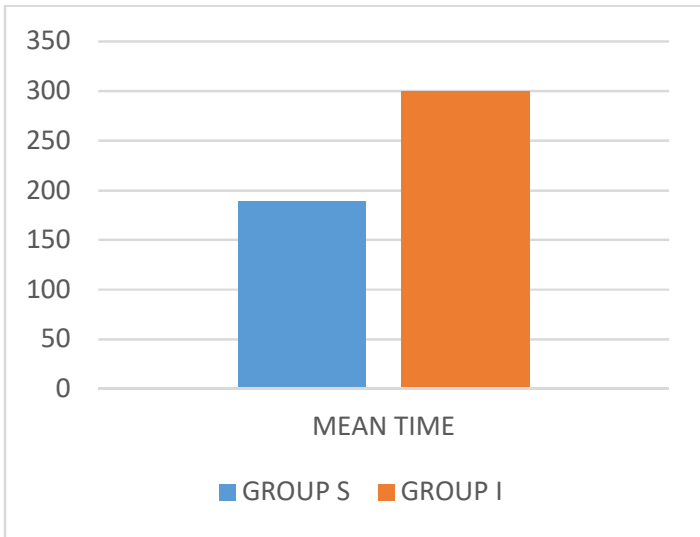

Figure 4: Mean access time between two groups $\mathrm{S}$ and $\mathrm{I}$ in seconds

Success of cannulation in Group $\mathrm{S}$ was 38 out of 40 patients $(95 \%)$, where as in Group I was 37 out of 40 patients $(92.5 \%)$ which was statistically not significant with $\mathrm{p}$ value of $>0.05$.

Complications in terms of arterial puncture was seen in 2 patients in Group $S$ and 1 patient Group I. Malposition in terms of cannula tip seen in ispsilateral IJV was seen in 3 patients in Group I and none in Group S. Pneumothorax was seen in 1 patient in Group I and none in Group S. All these complications in terms of arterial puncture, malposition and pneumothorax were not statistically significant between the groups with $\mathrm{p}$ value $>0.05$.

\section{Discussion}

The supraclavicular approach seems to be more comfortable than the jugular approach in a conscious patient. It will be of helpful, where the right jugular approach could be associated with cerebral perfusion pressure reduction, intracranial pressure elevation, and venous stasis like in neuroanesthesia. This method can be used successfully and relatively safely by inexperienced as well as experienced physician as a primary or alternative technique when other catheterization sites are not available. ${ }^{6}$

Success of cannulation in our study revealed, in Group S 95\%, where as in Group I was 92.5\% which was statistically not significant with $p$ value of $>0.05$. This was consistent with study done by Durrani et $\mathrm{al}^{4}$ where the overall success rate was $96.4 \%$ in supraclavicular group and $91.1 \%$ in infraclavicular group. Success rate is comparable and in more than $90 \%$, giving an opinion that both the approaches can be utilised when considering for subclavian venous cannulation.

Our study showed that in Group S 85\% of cannulas were secured in $1^{\text {st }}$ attempt, $10 \%$ in $2^{\text {nd }}$ attempt and 5\% had failed cannulation. In Group I, $67.5 \%$ were secured in $1^{\text {st }}$ attempt, $25 \%$ in $2^{\text {nd }}$ attempt and $7.5 \%$ had failed cannulation. These were not statistically significant with $p$ value of $>0.05$. This was comparable with Prasad et al ${ }^{5}$ study which had $72 \%$ of the catheterizations done in first attempt, $28 \%$ done in $2^{\text {nd }}$ attempt and $12 \%$ had failed cannulation. Slightly high failure rate seen in Prasad et al study were due to several causes like unable to locate the vein, arterial puncture, difficulty in the threading the guide wire, catheter entering into ipsilateral IJV. In our study failure rates were only due to inability to locate vein.

Time taken for successful cannulation in Group $\mathrm{S}$ were $188.96 \pm 37.19$ seconds and in Group I were $299.76 \pm 69.712$ seconds which was statistically significant with $\mathrm{p}$ value of $<0.001$. Thakur et $\mathrm{al}^{1}$, observed that the mean access time in supraclavicular approach was $4.30 \pm 1.02 \mathrm{mins}$, whereas in infraclavicular approach it was $6.07 \pm$ 2.14 mins.

Our study results are also in consistent with the above studies in terms of comparison of approaches in regard to mean access time for cannulation. But in our study the time taken for supraclavicular group was much less compared to other studies, indicating that supraclavicular approach by an experienced anaesthesiologist is the easiest and fastest way of central venous cannulation. So, it might be of great help during emergency and crisis situations.

Complications in terms of arterial puncture was seen in 1 patient in group $S$ and 3 patients ingroup I. Malposition in terms of cannula tip seen in ipsilateral IJV was seen in 3 patients in group I. Pneumothorax was seen in 1 patient in group I. All these complications in terms of arterial puncture, malposition and pneumothorax were not statistically significant between the groups with $\mathrm{p}$ value $>0.05$. The supraclavicular line offers another approach that appears at least as safe and possibly easier to perform with less misplacement than more frequently used lines. ${ }^{7}$ 
But these complications are of clinical significance, signifying supraclavicular group fares better than infraclavicular group in regard to complications.Complications in other studies like Pathiraja et $\mathrm{al}^{8}$, Aziz et $\mathrm{al}^{3}$ and Hussain et $\mathrm{al}^{2}$ were comparable with our study.

Ultrasound guidance reduces time to venous cannulation and reduces risk of complications during central venous access. ${ }^{9}$ Ultrasound is frequently used for placement of central venous catheters in the internal jugular and femoral veins but less commonly used in subclavian venous access, perhaps due to poor visualization of the vein from acoustic shadowing from the overlying clavicle. $^{10}$

Our institute had limitations for ultrasound use in our study. Probably by using ultrasound, the success rate would have improved further and complications would have been fewer.

Supraclavicular approach for subclavian vein is a comparable approach when compared to infraclavicular approach in terms of successful cannulation, number of attempts and complications like arterial puncture, malposition, pneumothorax and haemothorax. Supraclavicular approach is better than infraclavicular approach in terms of less mean time required for successful cannulation.

\section{Conclusions}

Supraclavicular approach is a faster way of cannulation of subclavian vein and is of great help during emergency situations when compared to infraclavicular approach. It can be an easy cannulation technique for the experienced physician and can be useful as an alternative to traditional approaches.Clinically complications rates are less in supraclavicular group as compared to infraclavicular approach.

\section{References}

1. Thakur A, Kaur K, Lamba A et al. Comparative evaluation of subclavian vein catheterisation using supraclavicular versus infraclavicular approach. Indian J Anaesth2014;58:160-4 https://doi.org/10.4103/0019-5049.130818 PMid:24963180 PMCid:PMC4050932

2. Hussain S, Khan RA, Iqbal M, Shafiq M. A comparative study of supraclavicular versus infraclavicular approach for central venous catheterization. Anaesth Pain \& Intensive Care 2011;15(1):13-16
3. Aziz N, Khan A, Iqbal J. Subclavian Vein Catheterization: Supraclavicular Versus Infraclavicular Approach. J. Med. Sci. (Peshawar, Print) 2013;21(4): 187-189

4. Durrani HD, Butt KJ, Sadaf S et al. Comparison of supraclavicular versus infraclavicular subclavian venous catheterization in a tertiary care hospital. JSZMC 2013;4(3):479-482.

5. Prasad PK, Sophia P, Lakshmi BS, Chandana K. Evaluation of the Efficacy of Supraclavicular Approach for Subclavian Vein Catheterization in Intensive Care Unit Patients: A Series of 50 Cases. International Journal of Scientific Study 2015; 3(1): 20-24.

6. Czarnik T, Gawda R, Perkowski T, Weron R. Supraclavicular Approach Is an Easy and Safe Method of Subclavian Vein Catheterization Even in Mechanically Ventilated Patient. Anesthesiology 2009; 111:334-9 https://doi.org/10.1097/ALN.0b013e3181ac461f PMid: 19602954

7. Patrick SP, Tijunelis MA, Johnson S, Herbert ME. Supraclavicular Subclavian Vein Catheterization: The Forgotten Centre Line. Review article. WestJEM. 2009; 10:110-114. PMid:19561831 PMCid:PMC2691520

8. Pathiraja C, Sharpe G, Woojner J, Stubbs R. Supraclavicular Subclavian Vein Catheterization In Morbidly Obese. Sri Lankan Journal of Anaesthesiology. 2009; 17(2): 65 - 68. https://doi.org/10.4038/slja.v17i2.1300

9. Lanspa M J, Fair J, Hirshberg E L, Grissom C K, Brown S M. Ultrasound-guided Subclavian Vein Cannulation Using a Micro-Convex Ultrasound Probe. Brief Communication. Ann Am Thorac Soc. 2014;11(4):583-586.

https://doi.org/10.1513/AnnalsATS.201311414BC

PMid:24611628 PMCid:PMC4225800

10. Byon HJ, Lee GW, Lee JH et al. Comparison between ultrasound-guided supraclavicular and infraclavicular approaches for subclavian venous catheterization in children-a randomized trial. British Journal of Anaesthesia 2013;111(5) :78892 https://doi.org/10.1093/bja/aet202 